\title{
Analytical Method in Solving Flow of Viscoelastic Fluid in a Porous Converging Channel
}

\author{
M. Esmaeilpour, ${ }^{1}$ Naeem Roshan, ${ }^{2}$ \\ Negar Roshan, ${ }^{3}$ and D. D. Ganji ${ }^{2}$ \\ ${ }^{1}$ Department of Mechanical Engineering, Islamic Azad University, Nowshahr-Branch, Nowshahr, Iran \\ ${ }^{2}$ Department of Mechanical Engineering, Babol Noshirvani University of Technology, Babol, Iran \\ ${ }^{3}$ Computer Engineering Department, Amir-Kabir University of Technology, Tehran, Iran
}

Correspondence should be addressed to M. Esmaeilpour, esmaeilpour.mehdi@gmail.com

Received 19 December 2010; Accepted 24 March 2011

Academic Editor: Mónica Clapp

Copyright (c) 2011 M. Esmaeilpour et al. This is an open access article distributed under the Creative Commons Attribution License, which permits unrestricted use, distribution, and reproduction in any medium, provided the original work is properly cited.

An analytical method, called homotopy perturbation method (HPM), is used to compute an approximation to the solution of the nonlinear differential equation governing the problem of two-dimensional and steady flow of a second-grade fluid in a converging channel. The table and figures are presented for influencing various parameters on the velocity field. The results compare well with those obtained by the numerical method. The method is straightforward and concise, and it can also be applied to other nonlinear evolution equations in mathematical physics.

\section{Introduction}

In recent years, there has been a considerable interest in the channel flow of non-Newtonian fluid because of its various applications in different fields of engineering. The problem of laminar flow of a viscous fluid in a parallel-walled channel was first studied by Berman [1] for two-dimensional case and the case of very cross-flow Reynolds number. In 1963, Rosenhead [2] explained this phenomenon more adequately by the theory of converging and diverging channel with a permeable wall and suction or injection at the wall whose magnitude is inversely proportional to the distance along the wall from the origin of the channel. Terrill [3] presented the new form for channel flow and considered suction at one wall and injection at the other wall where the rates of this injection and suction were equal. Some other researchers continued the solution of this phenomenon for different cases [4-7]. In 2001, Baris restated Terrill's problem by introducing a second-grade fluid and presented the effect of the elasticity 
of the fluid on the velocity distribution for different values of Reynolds number and crossflow Reynolds number [8].

In all of these cases, these problems do not admit analytical solution, so these equations should be solved using special techniques. In recent years, much attention has been devoted to the newly developed methods to construct an analytic solution of equation; such methods include the Adomian decomposition method [9-12], the homotopy perturbation method (HPM) [13-24], and the variational iteration method (VIM) [25-31]. HPM is the most effective and convenient one for both linear and nonlinear equations. This method does not depend on a small parameter. Using homotopy technique in topology, a homotopy is constructed with an embedding parameter $p \in[0,1]$, which is considered as a "small parameter." HPM has been shown to effectively, easily, and accurately solve a large class of linear and nonlinear problems with components converging rapidly to accurate solutions. HPM was first proposed by He [14-19] and was successfully applied to various engineering problems.

The organization of this paper is as follows: in Section 2, the mathematical framework of the homotopy perturbation method is illustrated. To present a clear overview of this method, Section 3 contains the description of the laminar flow of a second-grade viscoelastic fluid in a porous converging channel of total opening of $60^{\circ}$. In Section 4 , this analytical method is utilized to solve the nonlinear equation governing the described problem. Finally, some results are provided.

\section{Fundamentals of the Homotopy Perturbation Method}

To illustrate the homotopy perturbation method (HPM) for solving nonlinear differential equations, He $[14,15]$ considered the following non-linear differential equation:

$$
A(u)-f(r)=0, \quad r \in \Omega,
$$

with the boundary condition of

$$
B\left(u, \frac{\partial u}{\partial n}\right)=0, \quad r \in \Gamma
$$

where $A$ is a general differential operator, $B$ is a boundary operator, $f(r)$ is a known analytic function, $\Gamma$ is the boundary of the domain $\Omega$, and $\partial() / \partial n$ denotes differentiation along the normal vector drawn outwards from $\Omega$. The operator $A$ can generally be divided into two parts $L$ and $N$, where $L$ is linear and $N$ is nonlinear. Therefore, (2.1) can be rewritten as follows:

$$
L(u)+N(u)-f(r)=0, \quad r \in \Omega .
$$

Homotopy perturbation structure is shown as follows:

$$
H(v, p)=(1-p)\left[L(v)-L\left(u_{0}\right)\right]+p[A(v)-f(r)]=0,
$$


where

$$
v(r, p): \Omega \times[0,1] \longrightarrow R
$$

Equation (2.4) is equivalent to

$$
H(v, p)=L(v)-L\left(u_{0}\right)+p L\left(u_{0}\right)+p[N(v)-f(r)]=0 .
$$

So, we have

$$
H(v, 0)=L(v)-L\left(u_{0}\right)=0, \quad H(v, 1)=A(v)-f(r)=0 .
$$

The changing process of $p$ from zero to unity is just that of $H(v, p)$ from $L(v)-L\left(u_{0}\right)$ to $A(v)-f(r)$. In topology, this is called deformation and $L(v)-L\left(u_{0}\right)$ and $L(v)-L\left(u_{0}\right)$ are called homotopic. According to the homotopy perturbation method, the parameter $p$ is used as a small parameter, and the solution of (2.4) can be expressed as a series in $p$ in the form of

$$
v=v_{0}+p v_{1}+p^{2} v_{2}+\cdots
$$

When $p \rightarrow 1,(2.4)$ corresponds to the original one and (2.5) and (2.8) become the approximate solution of (2.3), that is,

$$
u=\lim _{p \rightarrow 1} v=v_{0}+v_{1}+v_{2}+\cdots
$$

The convergence of the series in (2.9) is discussed by He in [14, 15].

\section{Problem Statement and Mathematical Formulation}

In this section, we state the problem and present the governing equation. The phenomenon of two-dimensional non-Newtonian viscoelastic fluid flow in a converging channel whose wall has suction and injection is considered. The rates of these suction and injection in two walls are equal and vary in inverse proportion to the distance along the wall from the center of the channel. We assume that the wall which has suction is located in $\theta=+\alpha$ and the other wall which has injection of fluid is in $\theta=-\alpha$ (Figure 1). According to Figure $1, u(r, \theta)$ and $v(r)$ are velocity components in the directions of $r$ and $\theta$, respectively.

The governing equations for this problem are

continuity equation:

$$
\nabla \cdot V=0
$$






Figure 1: Schematic diagram of the physical system.

\section{Momentum equation:}

$$
\rho(V \cdot \nabla V)=\nabla \cdot T
$$

where $V$ is the velocity, $\rho$ is the density, and $T$ is The Cauchy stress tensor $[5,9]$ and it is presented as follows:

$$
T=-p_{0} I+A_{1}+\beta\left(A_{2}-A_{1}^{2}\right), \quad \beta=\alpha_{1}=-\alpha_{2} .
$$

Terrill and Roy and Nayak presented velocity field in the form of $[3,6]$

$$
\begin{gathered}
u(r, \theta)=\frac{U_{0} r_{0}}{r} f(\theta), \\
v(r)=\frac{V_{0} r_{0}}{r}
\end{gathered}
$$

where $V_{0}$ is the velocities of suction and injection at $\theta=+\alpha$ and $\theta=-\alpha$, respectively, at the typical length of $r_{0}$. Also, $U_{0}$ is the magnitude of the velocity in the direction of $r$ at the center line of the channel.

The boundary conditions for this problem are

$$
\begin{gathered}
u(r,-\alpha)=0, \\
u(r,+\alpha)=0, \\
u\left(r_{0}, 0\right)=-\left|U_{0}\right| .
\end{gathered}
$$


Using (3.1)-(3.5), we will have

$$
\begin{aligned}
\frac{\partial P}{\partial \theta}= & \frac{2 \mu U_{0} r_{0}}{r^{2}} f^{\prime}+\frac{2 \beta r_{0}^{2} U_{0}^{2}}{r^{4}} f^{\prime} f^{\prime \prime} \\
\frac{\partial P}{\partial r}= & \frac{\rho r_{0}^{2}}{r^{3}}\left(V_{0}^{2}+U_{0}^{2} f^{2}-U_{0} V_{0} f^{\prime}+\frac{\nu U_{0}}{r_{0}} f^{\prime \prime}\right) \\
& +\frac{\beta r_{0}^{2}}{r^{5}}\left(-8 V_{0}^{2}-8 U_{0}^{2} f^{2}+4 U_{0} V_{0} f^{\prime}-2 U_{0}^{2} f^{\prime 2}-4 U_{0}^{2} f f^{\prime \prime}+U_{0} V_{0} f^{\prime \prime \prime}\right),
\end{aligned}
$$

where, in these equations, prime denotes derivation with respect to $\theta$ and $v$ is the kinematic viscosity. Using (3.6) and eliminating the pressure term, (3.1) and (3.2) reduce to the following ordinary differential equation or similarity equation:

$$
f^{\prime \prime \prime}-R f^{\prime \prime}+2 \operatorname{Re} f f^{\prime}+4 f^{\prime}+N\left(-16 \operatorname{Re} f f^{\prime}+4 R f^{\prime \prime}-4 \operatorname{Re} f f^{\prime \prime \prime}+R f^{I V}\right)=0,
$$

where $R, \operatorname{Re}$, and $N$ are the cross-flow Reynolds number, Reynolds number, and elastic number, respectively.

The boundary conditions for this equation are

$$
f(-\alpha)=0, \quad f(0)=-1, \quad f(+\alpha)=0 .
$$

Equation (3.7) with the boundary conditions (3.8) is solved numerically by Bariş [9] for different cases of $R, R e$, and $N$. In this paper, we reconsider the governing equation and solve it by He's homotopy perturbation method.

\section{HPM Solutions for Velocity and Temperature Fields}

In this section, we will solve (3.7) using HPM. So, we construct the following homotopy for these equations:

$$
\begin{aligned}
H(f, p)= & (1-p)\left(f^{\prime \prime \prime}-f_{0}^{\prime \prime \prime}\right) \\
& +p\left(f^{\prime \prime \prime}-R f^{\prime \prime}+2 \operatorname{Re} f f^{\prime}+4 f^{\prime}\right. \\
& \left.+N\left(-16 \operatorname{Re} f f^{\prime}+4 R f^{\prime \prime}-4 \operatorname{Re} f f^{\prime \prime \prime}+R f^{I V}\right)\right)=0 .
\end{aligned}
$$

According to the definition of the HPM, we consider function $f(\theta)$ as follows:

$$
f=f_{0}+p f_{1}+p^{2} f_{2}+p^{3} f_{3}+\cdots
$$




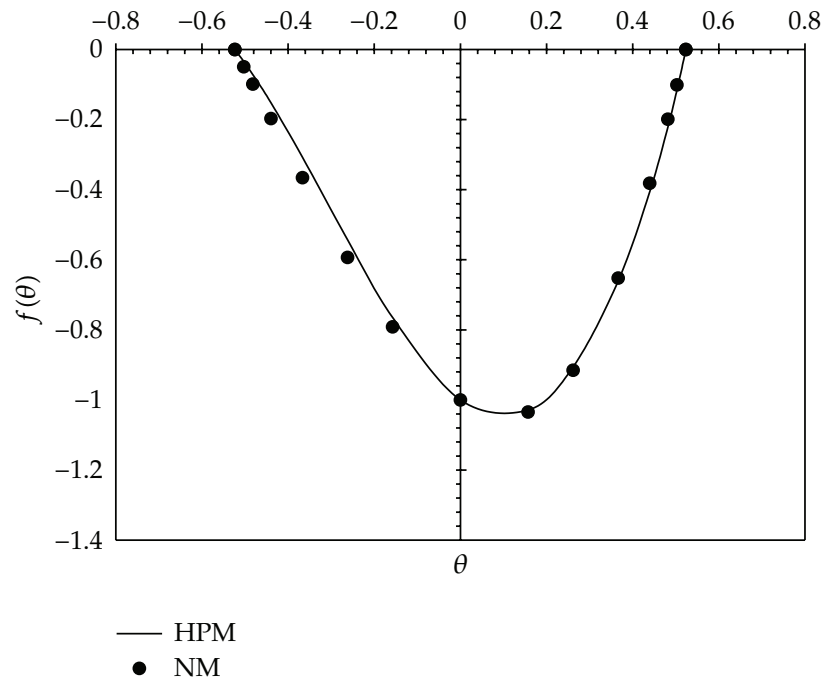

Figure 2: Comparison of HPM and the numerical method for $\operatorname{Re}=3, R=5$, and $N=0.015$.

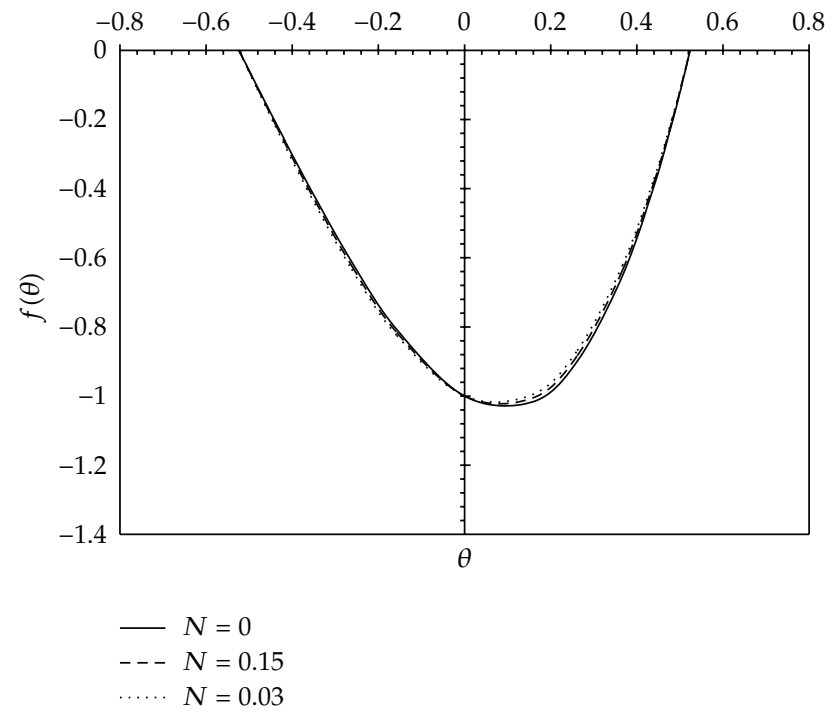

Figure 3: Velocity distribution for $\operatorname{Re}=0.5, R=2$, and different $N$ using HPM. 




Figure 4: Velocity distribution for $\operatorname{Re}=0.5, R=5$, and different $N$ using HPM.

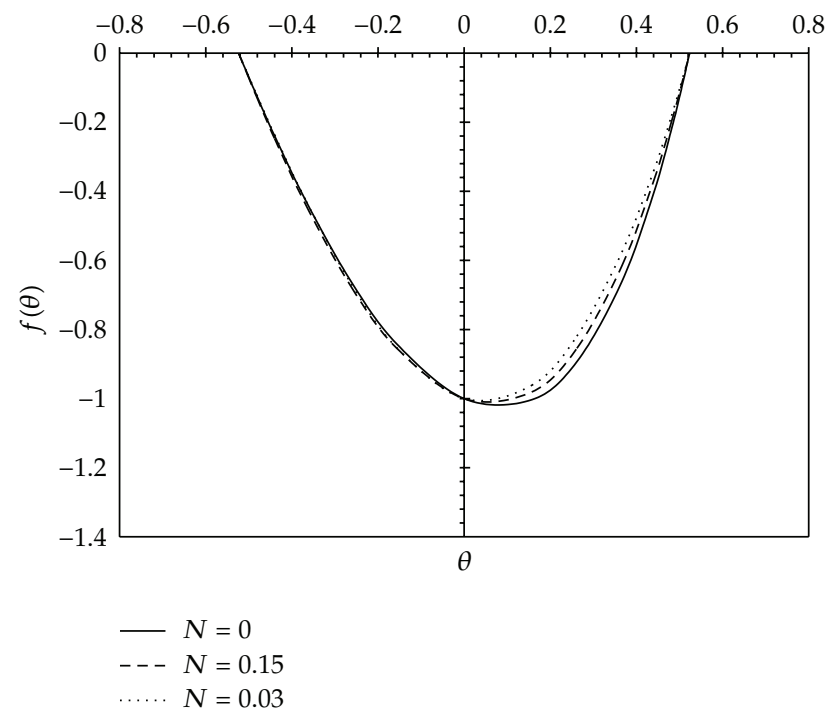

Figure 5: Velocity distribution for $\operatorname{Re}=5, R=2$, and different $N$ using HPM. 
Table 1: The results of HPM and NM methods for $\operatorname{Re}=3, R=5$, and $N=0.015$.

\begin{tabular}{lccc}
\hline$\theta$ & $f_{\mathrm{HPM}}$ & $f_{\mathrm{NM}}$ & $\left|f_{\mathrm{NM}}-f_{\mathrm{HPM}}\right|$ \\
\hline$-\pi / 6$ & 0.000024651 & 0.000000000 & 0.000025 \\
-0.5235 & -0.000133055 & -0.000232980 & 0.000100 \\
-0.5027 & -0.034635498 & -0.049303900 & 0.014668 \\
-0.4817 & -0.071891003 & -0.098813000 & 0.026922 \\
-0.4398 & -0.152402362 & -0.197161000 & 0.044759 \\
-0.3665 & -0.307655871 & -0.366006250 & 0.058350 \\
-0.2617 & -0.542915584 & -0.593305700 & 0.050390 \\
-0.1571 & -0.764703592 & -0.791658300 & 0.026955 \\
0.0000 & -1.000000000 & -1.000000000 & 0.000000 \\
0.1571 & -1.028797379 & -1.034518440 & 0.005721 \\
0.2617 & -0.905274553 & -0.915206190 & 0.009932 \\
0.3665 & -0.659877151 & -0.652557500 & 0.007320 \\
0.4398 & -0.405545492 & -0.381704720 & 0.023841 \\
0.4817 & -0.221073168 & -0.198909090 & 0.022164 \\
0.5027 & -0.115346628 & -0.100998040 & 0.014349 \\
0.5235 & -0.000482123 & -0.000485050 & 0.000003 \\
$+\pi / 6$ & 0.000096447 & 0.000000000 & 0.000096 \\
\hline
\end{tabular}

Assuming $f_{0}^{\prime \prime \prime}=0$ substituting $f(\theta)$ from (4.2) into (4.1), and using some simplification and rearranging based on powers of $p$-terms, we have

$$
\begin{gathered}
p^{0}: f_{0}^{\prime \prime \prime}=0, \\
f_{0}(-\alpha)=0, \quad f_{0}(0)=-1, \quad f_{0}(+\alpha)=0, \\
p^{1}: f_{1}^{\prime \prime \prime}-R f_{0}^{\prime \prime}+4 N R f_{0}^{\prime \prime}+2 \operatorname{Re} f_{0} f_{0}^{\prime}+N R f_{0}^{\mathrm{IV}} \\
+4 f_{0}^{\prime}-4 N \operatorname{Re} f_{0} f_{0}^{\prime \prime \prime}-16 N \operatorname{Re} f_{0} f_{0}^{\prime}=0, \\
f_{1}(-\alpha)=0, \quad f_{1}(0)=0, \quad f_{1}(+\alpha)=0, \\
p^{2}: f_{2}^{\prime \prime \prime}+4 f_{1}^{\prime}-16 N \operatorname{Re} f_{1} f_{0}^{\prime}+2 \operatorname{Re} f_{1} f_{0}^{\prime} \\
-16 N \operatorname{Re} f_{0} f_{1}^{\prime}-R f_{1}^{\prime \prime}-4 N \operatorname{Re} f_{0} f_{1}^{\prime \prime \prime}+4 N R f_{1}^{\prime \prime} \\
-4 N \operatorname{Re} f_{1} f_{0}^{\prime \prime \prime}+2 \operatorname{Re} f_{0} f_{1}^{\prime}+N R f_{1}^{\mathrm{IV}}=0, \\
f_{2}(-\alpha)=0, \quad f_{2}(0)=0, \quad f_{2}(+\alpha)=0,
\end{gathered}
$$


By using Maple software, we solve (4.3), (4.5), and (4.7) with considering boundary conditions (4.4), (4.6), and (4.8). We have obtained the 4-term approximations to $f(\theta)$, but for lack of space, only the first 3 terms produced are given below

$$
\begin{aligned}
f_{0}(\theta)= & \frac{36 \theta^{2}}{\pi^{2}}-1, \\
f_{1}(\theta)= & -\frac{114.048}{\pi^{4}} \theta^{6}+\frac{3.840}{\pi^{2}} \theta^{4}+\frac{56.400}{\pi^{2}} \theta^{3}-0.01866 \theta^{2}-1.56666 \theta \\
f_{2}(\theta)= & \frac{240.8693}{\pi^{6}} \theta^{10}-\frac{263.9396}{\pi^{6}} \theta^{8}-\frac{15.6408}{\pi^{4}} \theta^{8}-\frac{331.8253}{\pi^{4}} \theta^{7}+\frac{0.2821}{\pi^{2}} \theta^{6} \\
& +\frac{25.5052}{\pi^{4}} \theta^{6}+\frac{22.1088}{\pi^{2}} \theta^{5}+\frac{87.8688}{\pi^{4}} \theta^{5}+\frac{65.5788}{\pi^{2}} \theta^{4}-\frac{11.3040}{\pi^{2}} \theta^{3} \\
& -0.001991 \theta^{4}-0.363466 \theta^{3}-1.835365 \theta^{2}+0.247672 \theta
\end{aligned}
$$

According to the definition of the HPM in Section 2 ((2.8) and (2.9)), we consider 4order solution of $f(\theta)$ as following:

$$
f(\theta)=\sum_{i=0}^{4} f_{i}(\theta)
$$

In the case of $\operatorname{Re}=3, R=5$, and $N=0.015$ (Table 1 ), functions $f(\theta)$ are

$$
\begin{aligned}
f(\theta)= & 0.008022 \theta^{18}-0.062658 \theta^{16}-0.245778 \theta^{15}+0.110238 \theta^{14}+1.386855 \theta^{13} \\
& +2.362529 \theta^{12}-1.570382 \theta^{11}-8.762153 \theta^{10}-8.056363 \theta^{9}+5.259996 \theta^{8} \\
& +14.617810 \theta^{7}+5.696890 \theta^{6}-4.530889 \theta^{5}-4.098633 \theta^{4}+3.711309 \theta^{3} \\
& +4.284551 \theta^{2}-0.929478 \theta-1 .
\end{aligned}
$$

In the same manner, we have obtained the other cases for $\operatorname{Re}, R$, and $N$. The results are presented in Figures 2, 3, 4, and 5.

\section{Conclusion}

In this paper, we have successfully developed HPM to obtain the solutions of non-Newtonian viscoelastic fluid flow in a porous channel with suction and injection in their walls. The governing equation is solved for different cases of Reynolds number, Re, the cross-flow Reynolds number, $R$, and elastic number, $N$. It is apparently seen that homotopy perturbation method is a very powerful and efficient technique for solving different kinds of problems arising in various fields of science and engineering and present a rapid convergence for the solutions. 


\section{References}

[1] A. S. Berman, "Laminar flow in channels with porous walls," Journal of Applied Physics, vol. 24, pp. 1232-1235, 1953.

[2] L. Rosenhead, Laminar Boundary Layers, Clarendon Press, Oxford, UK, 1963.

[3] R. M. Terrill, "Slow laminar flow in a converging or diverging channel with suction at one wall and blowing at the other wall," Zeitschrift für angewandte Mathematik und Physik, vol. 16, no. 2, pp. 306-308, 1965.

[4] J. J. Choi, Z. Rusak, and J. A. Tichy, "Maxwell fluid suction flow in a channel," Journal of Non-Newtonian Fluid Mechanics, vol. 85, no. 2-3, pp. 165-187, 1999.

[5] R. S. Rivlin and J. L. Ericksen, "Stress-deformation relations for isotropic materials," Rational Mechanics and Analysis, vol. 4, pp. 323-425, 1955.

[6] J. S. Roy and P. Nayak, "Steady two dimensional incompressible laminar visco-elastic flow in a converging or diverging channel with suction and injection," Acta Mechanica, vol. 43, no. 1-2, pp. 129-136, 1982.

[7] R. L. Fosdick and K. R. Rajagopal, "Anomalous features in the model of "second order fluids"," Archive for Rational Mechanics and Analysis, vol. 70, no. 2, pp. 145-152, 1979.

[8] Y. Öztürk, A. Akyatan, and E. Şenocak, "Slow flow of the reiner-rivlin fluid in a coverging or diverging channel with suction and injection," Turkish Journal of Engineering and Environmental Sciences, vol. 22, no. 3, pp. 179-183, 1998.

[9] S. Bariş, "Flow of a second-grade visco-elastic fluid in a porous converging channel," Turkish Journal of Engineering and Environmental Sciences, vol. 27, no. 2, pp. 73-81, 2003.

[10] G. Adomian, Solving Frontier Problems of Physics: The Decomposition Method, vol. 60 of Fundamental Theories of Physics, Kluwer Academic Publishers, Dordrecht, The Netherlands, 1994.

[11] G. Adomian and R. Rach, "Noise terms in decomposition solution series," Computers E Mathematics with Applications, vol. 24, no. 11, pp. 61-64, 1992.

[12] A.-M. Wazwaz, "A new method for solving singular initial value problems in the second-order ordinary differential equations," Applied Mathematics and Computation, vol. 128, no. 1, pp. 45-57, 2002.

[13] S. A. Kechil and I. Hashim, "Non-perturbative solution of free-convective boundary-layer equation by Adomian decomposition method," Physics Letters, Section A, vol. 363, no. 1-2, pp. 110-114, 2007.

[14] J.-H. He, "Homotopy perturbation technique," Computer Methods in Applied Mechanics and Engineering, vol. 178, no. 3-4, pp. 257-262, 1999.

[15] J.-H. He, "A coupling method of a homotopy technique and a perturbation technique for non-linear problems," International Journal of Non-Linear Mechanics, vol. 35, no. 1, pp. 37-43, 2000.

[16] J.-H. He, "Homotopy perturbation method for bifurcation of nonlinear problems," International Journal of Nonlinear Sciences and Numerical Simulation, vol. 6, no. 2, pp. 207-208, 2005.

[17] J.-H. He, "Application of homotopy perturbation method to nonlinear wave equations," Chaos, Solitons and Fractals, vol. 26, no. 3, pp. 695-700, 2005.

[18] J.-H. He, "Some asymptotic methods for strongly nonlinear equations," International Journal of Modern Physics B, vol. 20, no. 10, pp. 1141-1199, 2006.

[19] J.-H. He and X.-H. Wu, "Construction of solitary solution and compacton-like solution by variational iteration method," Chaos, Solitons and Fractals, vol. 29, no. 1, pp. 108-113, 2006.

[20] L. Cveticanin, "Homotopy-perturbation method for pure nonlinear differential equation," Chaos, Solitons and Fractals, vol. 30, no. 5, pp. 1221-1230, 2006.

[21] M. El-Shahed, "Application of He's homotopy perturbation method to Volterra's integro-differential equation," International Journal of Nonlinear Sciences and Numerical Simulation, vol. 6, no. 2, pp. 163-168, 2005.

[22] M. Esmaeilpour and D. D. Ganji, "Application of He's homotopy perturbation method to boundary layer flow and convection heat transfer over a flat plate," Physics Letters. A, vol. 372, no. 1, pp. 33-38, 2007.

[23] M. Esmaeilpour, D. D. Ganji, and E. Mohseni, "Application of the homotopy perturbation method to micropolar flow in a porous channel," Journal of Porous Media, vol. 12, no. 5, pp. 451-459, 2009.

[24] P. Donald Ariel, "Homotopy perturbation method and the natural convection flow of a third grade fluid through a circular tube," Nonlinear Science Letters A, vol. 1, pp. 43-52, 2010.

[25] J.-H. He, "Variational iteration method-a kind of non-linear analytical technique: some examples," International Journal of Non-Linear Mechanics, vol. 34, no. 4, pp. 699-708, 1999.

[26] J.-H. He, "Variational iteration method for autonomous ordinary differential systems," Applied Mathematics and Computation, vol. 114, no. 2-3, pp. 115-123, 2000. 
[27] J.-H. He, "Variational theory for linear magneto-electro-elasticity," International Journal of Nonlinear Sciences and Numerical Simulation, vol. 2, no. 4, pp. 309-316, 2001.

[28] J.-H. He, "Variational principles for some nonlinear partial differential equations with variable coefficients," Chaos, Solitons and Fractals, vol. 19, no. 4, pp. 847-851, 2004.

[29] N. Bildik and A. Konuralp, "The use of variational iteration method, differential transform method and adomian decomposition method for solving different types of nonlinear partial differential equations," International Journal of Nonlinear Sciences and Numerical Simulation, vol. 7, no. 1, pp. 6570, 2006.

[30] A. A. Soliman, "Numerical simulation of the generalized regularized long wave equation by He's variational iteration method," Mathematics and Computers in Simulation, vol. 70, no. 2, pp. 119-124, 2005.

[31] N. H. Sweilam and M. M. Khader, "Variational iteration method for one dimensional nonlinear thermoelasticity," Chaos, Solitons and Fractals, vol. 32, no. 1, pp. 145-149, 2007. 


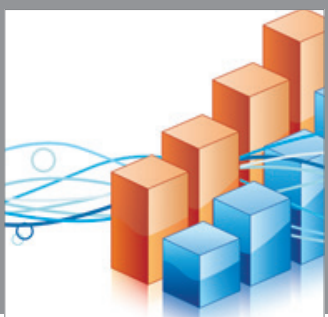

Advances in

Operations Research



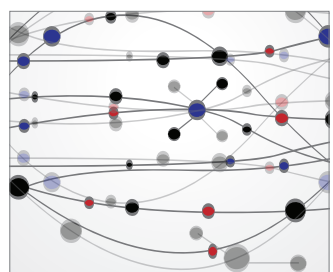

\section{The Scientific} World Journal
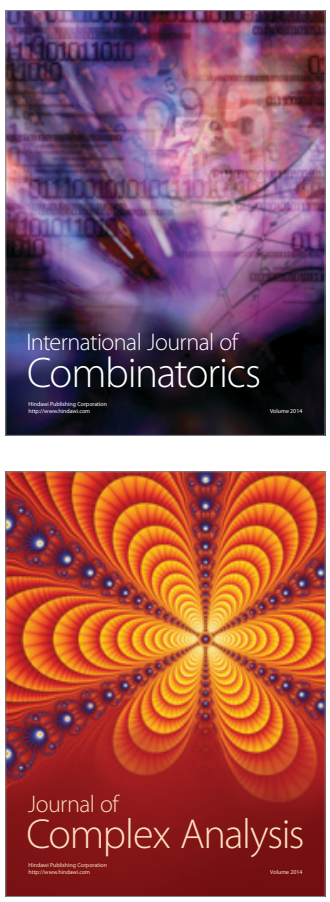

International Journal of

Mathematics and

Mathematical

Sciences
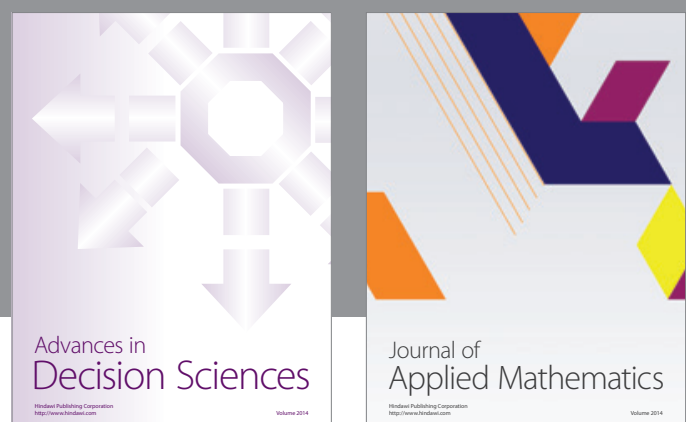

Journal of

Applied Mathematics
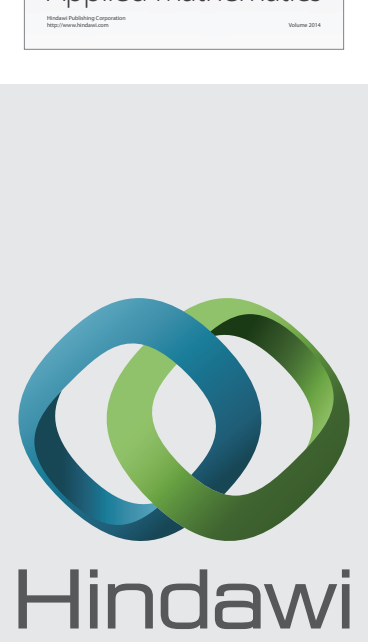

Submit your manuscripts at http://www.hindawi.com
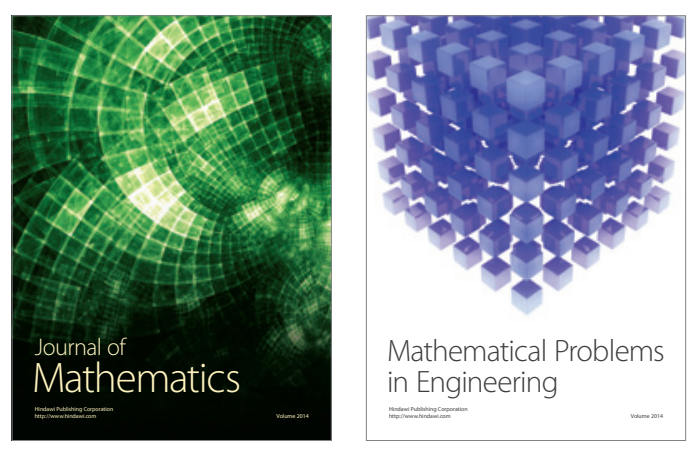

Mathematical Problems in Engineering
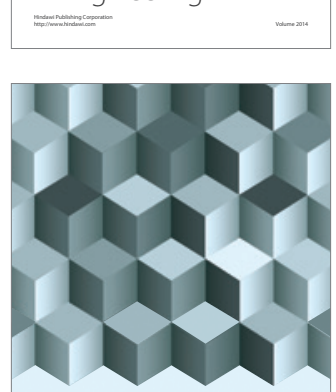

Journal of

Function Spaces


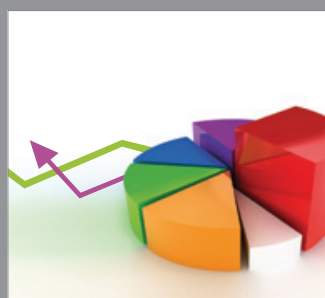

ournal of

Probability and Statistics

Promensencen
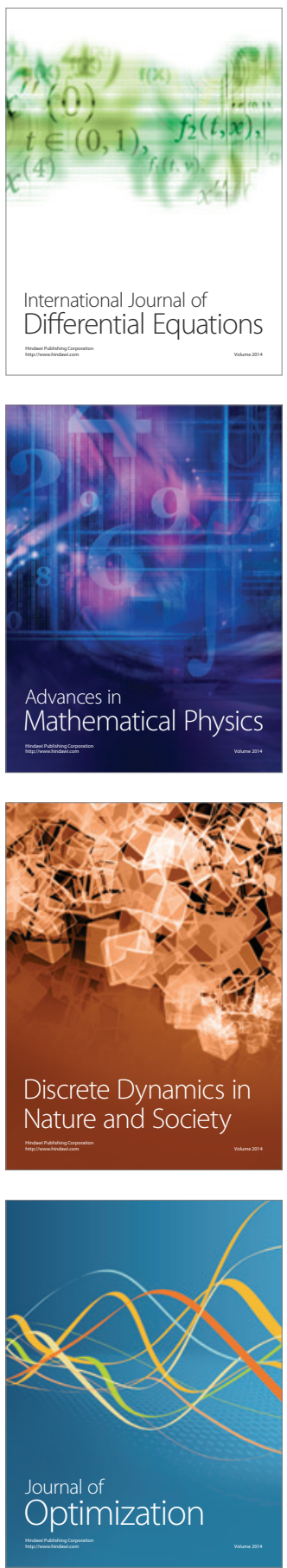